\title{
THE GREAT IMITATOR - EMA POSITIVE GLIOBLASTOMA MULTIFORME
}

\author{
George St. Stoyanov, Deyan Dzhenkov, Peter Ghenev \\ Department of General and Clinical Pathology, Forensic Medicine and Deontology, \\ Faculty of Medicine, Medical University of Varna
}

\begin{abstract}
INTRODUCTION: Glioblastoma multiforme (GBM) has always been a diagnostic challenge for pathologists. As a rare oncological entry with astrocytic differentiation, it can manifest itself in a variety of histomorphological forms, mimic other tumors and it often has varying immunohistochemical (IHC) profiles, further challenging the process of its verification.

MATERIALS AND METHODS: Four pathologically verified cases of GBM, registered at the St. Marina University Hospital, Varna, Bulgaria were retrieved from the central pathological archive. The cases were tested and reviewed based on their hematoxylin and eosin (H\&E) profiles and IHC reactions with GFAP used as a glial differentiation marker, Vimentin - as a positive IHC control and EMA, an epithelial marker, non-reactive in healthy brain tissue.

RESULTS: As expected all GBM cases had the histomorphological hallmarks of the tumor on the H\&E stain. They were diagnostically positive for GFAP and had a strong positive IHC reaction with Vimentin. Three out of the four cases also revealed a varying in intensity reaction with EMA, with one case having a weak reaction in individual cells that could not be considered diagnostic and the other two cases having a diffuse positive reaction in most of the tumor cells.

CONCLUSION: In the age of immunohistochemistry, GBM continues to expand the set of IHC markers that react with it, although several of them such as Cytokeratin AE1/AE3 and EMA, as demonstrated in this study, should be non-reacting as they react with proteins normally present only in epithelial cells and absent in healthy brain tissue. This can often be misleading and, in certain cases, lead to histopathological misdiagnosis.
\end{abstract}

Keywords: GBM, IHC, EMA, CNS tumor, pathology, antibody mimicry

Address for correspondence:

George St. Stoyanov

Department of General and Clinical Pathology, Forensic

Medicine and Deontology

Faculty of Medicine

Medical University of Varna

55 Marin Drinov St

9002 Varna

e-mail:georgi.geesh@gmail.com

Received: February 25, 2017

Accepted: March 16, 2017

\section{INTRODUCTION}

Glioblastoma multiforme (GBM) is a World Health Organization (WHO) grade IV malignant astrocytoma, widely considered as one of the most malignant primary intracranial tumors and the most malignant one with astrocytic differentiation (1). GBM is also one of the most common entries in neuro-oncology and per some studies its incidence even outweighs that of the central nervous system (CNS) metastatic disease (2-8). GBM presents itself as a 
challenge for the neuropathologist as on the hematoxylin and eosin (H\&E) stain it can present itself in a wide variety of histomorphological forms, mimic other primary and even CNS metastatic tumors (9).

Even in the age of immunohistochemistry GBM remains a diagnostic challenge due to the varying immunohistochemical (IHC) profiles it often has (10-12). Further on, GBM continues to expand the set of IHC markers that react positively with it, although some of the target proteins are not found in healthy astrocytes and are hallmark proteins of other tissue and cell types, with different embryonic origin (10-12).

These specifics of GBM further increase the difficulty of distinguishing between primary and metastatic lesions in some cases and present a diagnostic dilemma for untrained pathologists.

The aim of the study was to evaluate the distinguishing capabilities of epithelial membrane antigen (EMA) for GBM and metastatic epithelial lesions, as false positive results for some other epithelial markers such as cytokeratin (CK), mainly CK AE1/AE3, in GBM tissue samples have already been reported (10-12).

\section{MATERIALS AND METHODS}

Four cases of histologically verified GBM, registered in the St. Marina University Hospital, Varna, Bulgaria were retrieved from the central pathological archive. Their histomorphological profile and IHC reactions with glial fibrillary acidic protein (GFAP) and vimentin (Vim) were reevaluated and new slides were IHC stained for EMA, prepared from the original paraffin-embedded tissue sections.

All IHC slides were prepared using ready-touse Dako catalogue primary and secondary antibodies and chromogen on a Dako Autostainer Link48, with the preprogrammed IHC protocols from paraffin-embedded tissue sections.

GFAP is a class III intermediate cytoskeletal filament with a $50 \mathrm{kD}$ molecular weight, found in all astrocytes, other glial cells, and some pericytes. The GFAP IHC stain, performed with a polyclonal rabbit antibody, was used in the context of this study, as a glioma control stain (13-14).

Vim is also a class III intermediate cytoskeletal filament with a $57 \mathrm{kD}$ molecular weight, found in all cells with a mesenchymal origin, astrocytes and others, normally not expressed in most types of epithelial cells. In the context of this study, due to its wide range of positive reactions, the IHC Vim stain, performed with a murine monoclonal antibody, was used as a positive control for IHC (15).

EMA is a surface glycoprotein found on the outer cellular membrane of most epithelial cell types and some hematopoietic cells, but it is non-reacting in healthy brain tissue. As such the EMA antibody is often used in neuropathology to distinguish between epithelial metastases and primary intracranial tumors, except for ependymoma. The IHC stain was performed with a murine monoclonal antibody (16).

Digital images of the H\&E and IHC slides were obtained on a Leika Aperio AT2 automated slide scanner using the pre-calibrated scanner settings.

\section{RESULTS}

As expected all four GBM cases had a strong, diagnostically positive reaction with GFAP and Vim, very characteristic of GBM (Fig. 1).

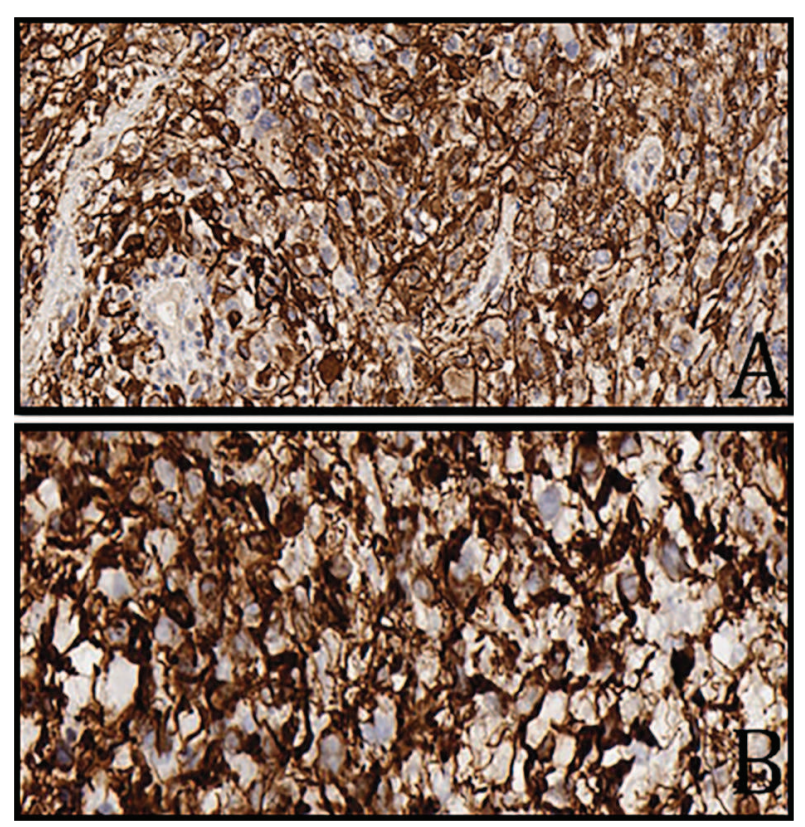

Fig. 1. IHC reaction of GBM with GFAP (A) and Vim (B). Original magnification $x 400$

However, only one case had a completely negative IHC reaction with EMA and one of the remaining three had a patchy weak positive reaction in individual cells. The remaining two cases had a dif- 
fuse weak positive reaction with EMA, which if interpreted out of the context of the H\&E and other IHC stains would carry a diagnostic weight (Fig. 2). The two cases with an EMA-positive IHC reaction were however weaker when compared to the IHC reaction with GFAP and Vim on neighboring slides of the same tissue samples and had an uncharacteristic cytoplasmic reaction compared to the surface nature of the EMA molecule (Fig. 3).
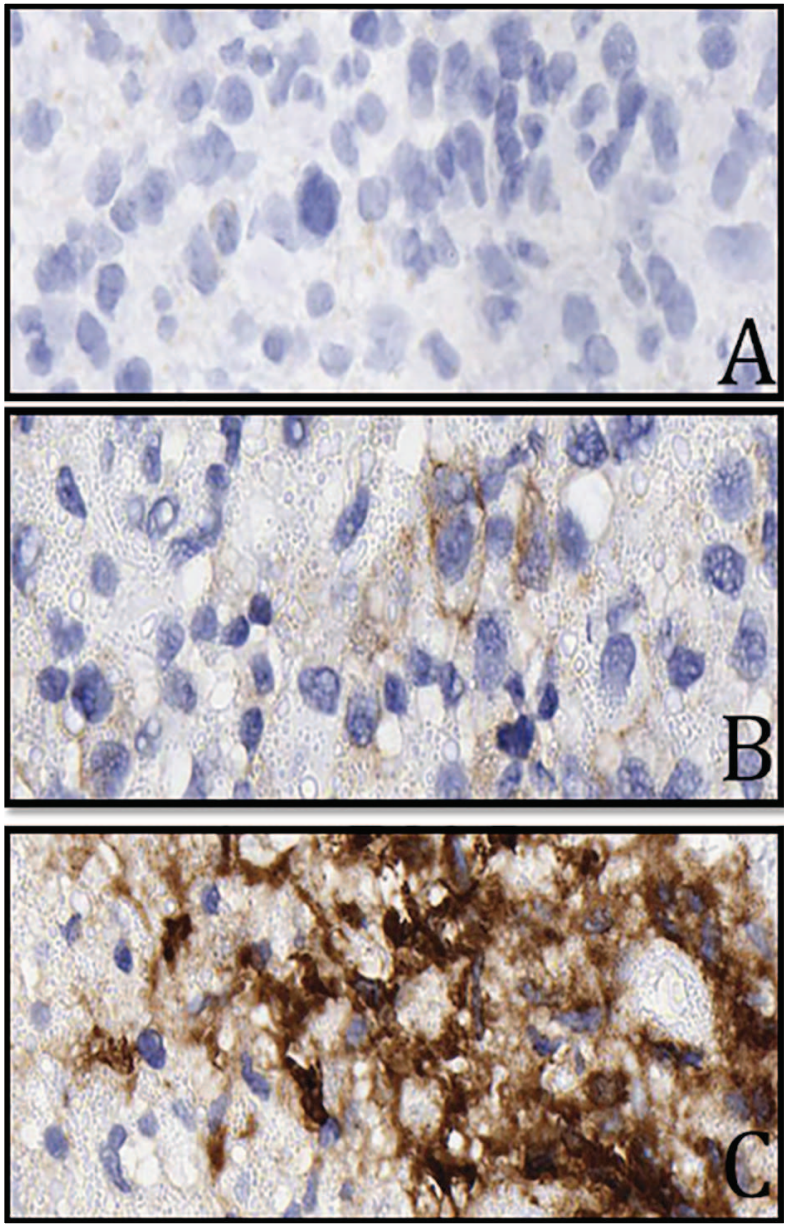

Fig. 2. IHC reaction of GBM with EMA - negative (A), weak positive $(B)$ and strong $(C)$. Original magnification $x 400$

The reposted results give rise to the question why some GBM tissue samples react positively with antibodies targeting proteins normally not present and non-reacting in healthy astrocytes, which are hallmark proteins of cell of a different tissue type and embryonic origin.
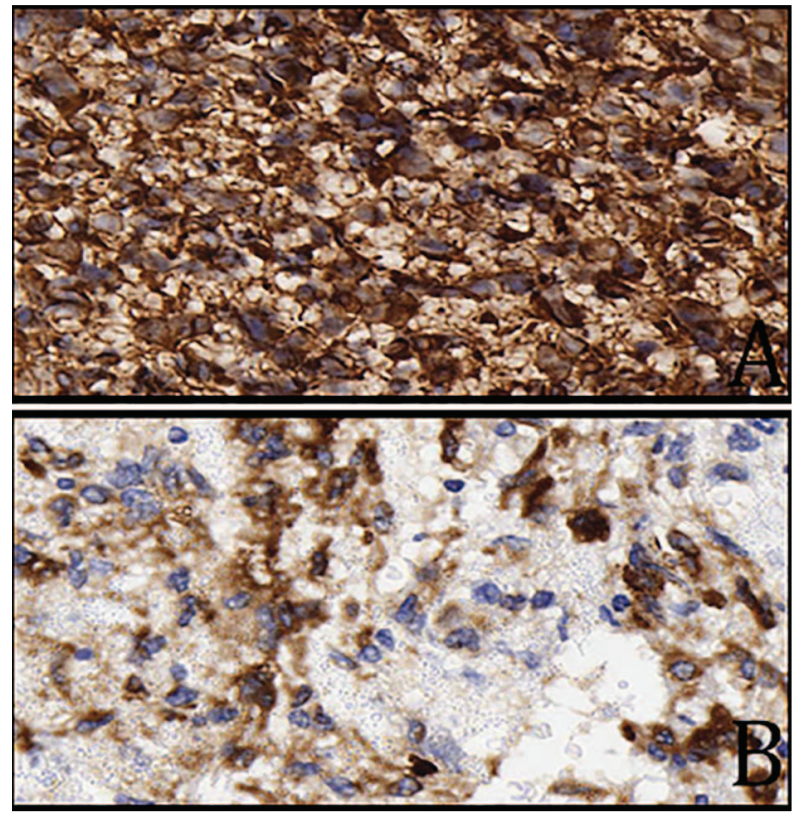

Fig. 3. Comparison between IHC reaction of GBM with GFAP (A) and EMA (B). Note the reaction with EMA is weaker than that of GFAP. Original magnification $x 400$

\section{DISCUSSION}

IHC, although a specific in vitro immunology based test, has been known to give false positive reactions in cases of three-dimensional conformational similarity between specific sequences (epitomes) of cellular antigens and the target antibody. In GBM, such a phenomenon has already been established between the AE3 fraction of the CK AE1/AE3 antibody cocktail (a pan-epithelial marker) and the GFAP produced from neoplastic astrocytes $(10-12,17)$.

Such a correlation has not yet been established for EMA. However, based on the similarity of the reported results, some similar reports, specifics of the targeted membrane molecules and cytoplasmic IHC reactions in GBM tissue samples, it seems to be highly likely that EMA is another candidate for a GBM false positive IHC reaction, not based on the true expression of EMA in GBM (18-20).

GBM has been known to have a great variety of molecular types and subtypes, which have only very recently been demonstrated to be associated with different histomorphological forms of the tumor (21-28). It is yet unknown whether these mutations would play a role in the IHC profile, but such a correlation does not seem unlikely. 


\section{CONCLUSION}

Due to the specifics of IHC, it is important to never interpret the result of one marker out of the context of H\&E and other IHC markers. The IHC reaction with EMA is another candidate reaction to be included into the expanding non-diagnostic spectrum of GBM IHC reactions, which requires increased attention when interpreting the results and pathological differential diagnosis between a CNS metastatic epithelial tumor and GBM.

The reported results are important for the evasion of a pathological misdiagnosis of GBM and CNS metastatic lesions of epithelial origin and the prevention of an inadequate use of medical resources targeted at the search for a primary locus of the metastatic lesion (X-ray, CT, MRI, PET-CT, etc.), when such tumor is in fact non-existent (29).

\section{ACKNOWLEDGEMENTS}

The authors would also like to thank all the medical and non-medical personnel, past and present, of the St. Marina University Hospital, Varna, Bulgaria, who while performing their medical and humanitarian duties also contributed to the completion of this study.

\section{REFERENCES}

1. Louis DN, Ohgaki H, Wiestler OD, Cavenee WK, Burger PC, Jouvet A, Scheithauer BW, Kleihues P. The 2007 WHO classification of tumours of the central nervous system. Acta Neuropathol 2007;114(2):97-109.

2. Dolecek TA, Propp JM, Stroup NE, Kruchko C. CBTRUS statistical report: primary brain and central nervous system tumors diagnosed in the United States in 2005-2009. Neuro Oncol 2012;14 Suppl 5:1-49.

3. Ostrom QT, Gittleman H, Farah P, Ondracek A, Chen Y, Wolinsky Y, Stroup NE, Kruchko C, Barnholtz-Sloan JS. CBTRUS statistical report: Primary brain and central nervous system tumors diagnosed in the United States in 2006-2010. Neuro Oncol 2013;15 Suppl 2:1-56.

4. Ostrom QT, Gittleman H, Liao P, Rouse C, Chen Y, Dowling J, Wolinsky Y, Kruchko C, BarnholtzSloan J. CBTRUS statistical report: primary brain and central nervous system tumors diagnosed in the United States in 2007-2011. Neuro Oncol 2014;16 Suppl 4:1-63.
5. Ostrom QT, Gittleman H, Fulop J, Liu M, Blanda R, Kromer C, Wolinsky Y, Kruchko C, Barnholtz-Sloan JS. CBTRUS Statistical Report: Primary Brain and Central Nervous System Tumors Diagnosed in the United States in 2008-2012. Neuro Oncol 2015;17 Suppl 4:1-62.

6. Fogelholm R, Uutela T, Murros K. Epidemiology of central nervous system neoplasms. A regional survey in Central Finland. Acta Neurol Scand 1984;69(3):129-36.

7. Guomundsson KR. A survey of tumors of the central nervous system in Iceland during the 10-year period 1954-1963. Acta Neurol Scand 1970;46(4):538-52.

8. Walker AE, Robins M, Weinfeld FD. Epidemiology of brain tumors: the national survey of intracranial neoplasms. Neurology 1985;35(2):219-26.

9. Kepes JJ. Astrocytomas: old and newly recognized variants, their spectrum of morphology and antigen expression. Can J Neurol Sci 1987;14(2):109-21.

10. Kriho VK, Yang HY, Moskal JR, Skalli O. Keratin expression in astrocytomas: an immunofluorescent and biochemical reassessment. Virchows Arch 1997;431(2):139-47.

11. Goswami C, Chatterjee U, Sen S, Chatterjee S, Sarkar S. Expression of cytokeratins in gliomas. Indian J Pathol Microbiol 2007;50(3):478-81.

12. Cosgrove MM, Rich KA, Kunin SA, Sherrod AE, Martin SE. Keratin intermediate filament expression in astrocytic neoplasms: analysis by immunocytochemistry, western blot, and northern hybridization. Mod Pathol 1993;6(3):342-7.

13. GFAP - DAKO antibody description. [Internet] Dako c2016. Available from: http://www.dako.com/ dist/ar48/p235466/prod_products.htm

14. Eng LF, Ghirnikar RS, Lee YL. Glial fibrillary acidic protein: GFAP-thirty-one years (1969-2000). Neurochem Res 2000;25(9-10):1439-51.

15. Vimentin - DAKO antibody description. [Internet] Dako c2016. Available from: http://www.dako. com/dist/ar48/p235256/prod_products.htm

16. EMA - DAKO antibody description. [Internet] Dako c2016. Available from: http://www.dako.com/ dist/ar48/p235221/prod_products.htm

17. Cosgrove M, Fitzgibbons PL, Sherrod A, Chandrasoma PT, Martin SE. Intermediate filament expression in astrocytic neoplasms. Am J Surg Pathol 1989;13(2):141-5. 
18. Hasselblatt M, Paulus W. Sensitivity and specificity of epithelial membrane antigen staining patterns in ependymomas. Acta Neuropathol 2003;106(4):385-8.

19. He MX, Wang JJ. Rhabdoid glioblastoma: case report and literature review. Neuropathology 2011;31(4):421-6.

20. Preusser M, Hoischen A, Novak K, Czech T, Prayer D, Hainfellner JA, Baumgartner C, Woermann FG, Tuxhorn IE, Pannek HW, Bergmann M, Radlwimmer B, Villagrán R, Weber RG, Hans VH. Angiocentric glioma: report of clinico-pathologic and genetic findings in 8 cases. Am J Surg Pathol 2007;31(11):1709-18.

21. DeAngelis LM, Mellinghoff IK. Virchow 2011 or how to ID $(\mathrm{H})$ human glioblastoma. J Clin Oncol 2011;29(34):4473-4.

22. Crespo I, Vital AL, Gonzalez-Tablas M, Patino Mdel C, Otero A, Lopes MC, de Oliveira C, Domingues P, Orfao A, Tabernero MD. Molecular and Genomic Alterations in Glioblastoma Multiforme. Am J Pathol 2015;185(7):1820-33.

23. Masui K, Mischel PS, Reifenberger G. Molecular classification of gliomas. Handb Clin Neurol 2016;134:97-120.

24. Wirsching HG, Galanis E, Weller M. Glioblastoma. Handb Clin Neurol 2016;134:381-97.

25. Masui K, Komori T. Molecular Genetics as Best Evidence in Glioma Diagnostics. Brain Nerve 2016;68(3):253-61.

26. Vigneswaran K, Neill S, Hadjipanayis CG. Beyond the World Health Organization grading of infiltrating gliomas: advances in the molecular genetics of glioma classification. Ann Transl Med 2015;3(7):95.

27. Verhaak RG, Hoadley KA, Purdom E, Wang V, Qi Y, Wilkerson MD, Miller CR, Ding L, Golub T, Mesirov JP, Alexe G, Lawrence M, O'Kelly M, Tamayo P, Weir BA, Gabriel S, Winckler W, Gupta S, Jakkula L, Feiler HS, Hodgson JG, James CD, Sarkaria JN, Brennan C, Kahn A, Spellman PT, Wilson RK, Speed TP, Gray JW, Meyerson M, Getz G, Perou $\mathrm{CM}$, Hayes DN. Integrated genomic analysis identifies clinically relevant subtypes of glioblastoma characterized by abnormalities in PDGFRA, IDH1, EGFR, and NF1. Cancer Cell 2010;17(1):98-110.

28. Neumann JE, Dorostkar MM, Korshunov A, Mawrin C, Koch A, Giese A, Schüller U. Distinct Histomorphology in Molecular Subgroups of Glioblasto- mas in Young Patients. J Neuropathol Exp Neurol 2016 [Epub ahead of print].

29. Antoch G, Vogt FM, Freudenberg LS, Nazaradeh F, Goehde SC, Barkhausen J, Dahmen G, Bockisch A, Debatin JF, Ruehm SG. Whole-body dual-modality PET/CT and whole-body MRI for tumor staging in oncology. JAMA 2003;290(24):3199-206. 